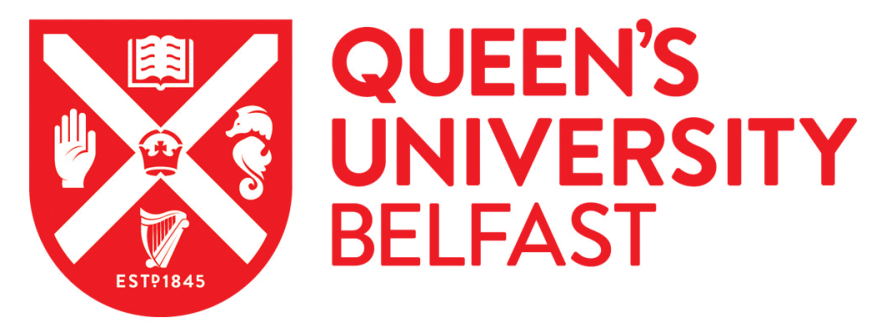

\title{
Simulation Based Process Design Methods for Maintenance Planning
}

Butterfield, J., \& McEwan, W. (2011). Simulation Based Process Design Methods for Maintenance Planning. In I. Ng, G. Parry, P. Wild, D. McFarlane, \& P. Tasker (Eds.), Complex Engineering Service Systems (pp. 335-354). Springer. https://doi.org/10.1007/978-0-85729-189-9_18

\section{Published in:}

Complex Engineering Service Systems

Queen's University Belfast - Research Portal:

Link to publication record in Queen's University Belfast Research Portal

\section{General rights}

Copyright for the publications made accessible via the Queen's University Belfast Research Portal is retained by the author(s) and / or other copyright owners and it is a condition of accessing these publications that users recognise and abide by the legal requirements associated with these rights.

Take down policy

The Research Portal is Queen's institutional repository that provides access to Queen's research output. Every effort has been made to ensure that content in the Research Portal does not infringe any person's rights, or applicable UK laws. If you discover content in the Research Portal that you believe breaches copyright or violates any law, please contact openaccess@qub.ac.uk. 


\begin{tabular}{|l|lll|}
\hline Layout: T1 Standard SC & Book ID: 192632_1_En & Book ISBN: 978-0-85729-188-2 \\
Chapter No.: 18 & Date: 14-5-2011 & Page: 333/352 \\
\hline
\end{tabular}

\title{
1 Chapter 18 \\ 2 Simulation Based Process Design Methods 3 for Maintenance Planning
}

\author{
4 Joe Butterfield and William McEwan
}

\begin{abstract}
The primary objective of this work is to use simulation methods for the development of optimal service support procedures using an integrated Product, Process and Resource (PPR) structure. Mid life fatigue modifications required on a sub-system within an existing aerospace platform that has been used to demonstrate the utility of this approach in supporting the transition of an original equipment manufacturer (OEM) to availability contracting. Other objectives of the work were to show how significant cost drivers can be identified and quantified through the virtual development of work breakdown structures (WBS) for service support processes and to show how the mechanisms used to develop optimal processes, can produce animated instructional materials which enhance organisational learning as processes evolve. This supports the effective communication of methods and work breakdown structures between the technical author and service personnel. Although this work has been completed using an aerospace sub-system as a demonstrator, the outcomes are equally applicable to other platforms which utilise complex engineering systems. The results of this work have system level significance in reducing risk in service provision through the support of value co-creation. The simulation outputs also provide data for higher level cost modelling which in turn, informs the strategy required for supply chain engagement through incentivisation.
\end{abstract}

\subsection{Introduction}

The last $10-15$ years have seen momentous changes in global socio-economic conditions as well as a significant shift in military strategy as world orders changed after the fall of communism. According to Spreen, this resulted in a drop in

\footnotetext{
J. Butterfield $(\bowtie) \cdot$ W. McEwan

School of Mechanical and Aerospace Engineering, Queen's University Belfast, Ashby

Building, Stranmillis Rd, Belfast, BT9 5AH, UK

e-mail: j.butterfield@qub.ac.uk
}

I. Ng et al. (eds.), Complex Engineering Service Systems, Decision Engineering, DOI: 10.1007/978-0-85729-189-9_18, @ Springer-Verlag London Limited 2011 


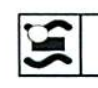

334

Fig. 18.1 Evolutionary stages of a learning company (Pedler et al. 1996)
Book ISBN: 978-0-85729-188.2

Page: 334/352

J. Butterfield and W. McEwan

demand for military aircraft particularly in Europe during the 1990s and although the emergence of new terrorist related threats prompted a recovery in the demand for defence related equipment in the US after 2001, the probability that the number of new military aircraft programs will recover to cold war levels is exceptionally low. These circumstances have resulted in a contraction in the demand for new product development and an increase in the pressure to keep legacy systems in service for longer. OEMs are therefore, increasingly evolving from product suppliers to service providers. Challenging commercial conditions have also resulted in end users re-structuring their own core businesses. A faltering world economy has placed enormous pressures on government finances and despite clear operational needs, defence spending has been highly constrained in recent years. The net result of these circumstances and changing behaviours has been the need for the OEM to integrate and manage support service activities in partnership with the customer to deliver the availability of a given platform or product. This improves the likelihood of operational sustainability for the OEM through shared commercial risks while reducing the cost of ownership for the customer with equivalent or improved platform availability.

In order to complete the transition to 'availability contracting', the OEM must move beyond core business activities based on pure manufacture and supply to become involved in the broader product lifecycle. This fundamental shift in commercial practice must take place in partnership with the customer and it represents a significant challenge at all organisational and technical levels within both organisations. A successful, sustainable outcome will depend on the extent to which the both parties become a 'Learning Organisation'. This will require the effective amalgamation of key business elements of the previously separate enterprises and both the OEM and the customer will have to pass through the evolutionary stages proposed by Pedler et al. (1996) as shown in Fig. 18.1, from simply surviving as separate entities, through adaptation to joint sustainability. 


\begin{tabular}{|l|lll|}
\hline $\mathbf{1}$ & Layout: T1 Standard SC & Book ID: 192632_1_En & Book ISBN: 978-0-85729-188-2 \\
Chapter No.: 18 & Date: $14-5-2011$ & Page: $335 / 352$ \\
\hline
\end{tabular}

18 Simulation Based Process Design Methods

Table 18.1 Characteristics of the Learning Company

\begin{tabular}{|c|c|}
\hline $\begin{array}{l}\text { Learning approach to } \\
<- \text { strategy }\end{array}$ & Pilots and experiments used to inform direction \\
\hline $\begin{array}{l}\text { Participative policy } \\
<- \text { making }\end{array}$ & All stakeholders contribute to policy making \\
\hline Informating & $\begin{array}{l}\text { Use of I.T. to automate and distribute information thereby empowering } \\
\leftarrow \text { operatives to act on their own initiative }\end{array}$ \\
\hline $\begin{array}{l}\text { Formative accounting } \\
\leftarrow \text { and control }\end{array}$ & $\begin{array}{l}\text { One aspect of informating opening up budgeting, reporting and } \\
\leftarrow \text { accounting to broader enterprise }\end{array}$ \\
\hline $\begin{array}{l}\text { Formative accounting } \\
\leftarrow \text { and control }\end{array}$ & $\begin{array}{l}\text { One aspect of informating opening up budgeting, reporting and } \\
\leftarrow \text { accounting to broader enterprise }\end{array}$ \\
\hline Internal exchange & $\begin{array}{l}\text { All internal units and departments are effectively customers and } \\
\leftarrow \text { suppliers in a supply chain leading to the customer. Contracting } \\
\longleftarrow \text { with and learning from one another }\end{array}$ \\
\hline Reward flexibility & $\begin{array}{l}\text { Greater participation creates the need for flexible and creative } \\
\leftarrow \text { monetary/non- monetary rewards }\end{array}$ \\
\hline Enabling structures & $\begin{array}{l}\text { Roles, departments, organisational charts, procedures and processes } \\
\leftarrow \text { can be viewed as structures that can be used to meet job, user or } \\
\leftarrow \text { innovation requirements }\end{array}$ \\
\hline $\begin{array}{l}\text { Boundary (interface) } \\
\text { controls }\end{array}$ & $\begin{array}{l}\text { Used for 'environmental scanning' by those who have contact with } \\
\leftarrow \text { external users, customers, suppliers, clients, business partners etc. } \\
\leftarrow \text { Processes used for data handling passing into (and out) of the } \\
\leftarrow \text { enterprise }\end{array}$ \\
\hline Inter-company learning & $\begin{array}{l}\text { Through joint ventures and other learning alliances, organisations } \\
\leftarrow \text { learn from other companies. This is facilitated by joint meetings for } \\
\leftarrow \text { mutually beneficial information exchange }\end{array}$ \\
\hline Learning climate & $\begin{array}{l}\text { Management facilitating experimentation and learning from } \\
\leftarrow \text { experience through questioning, feedback and support. This is } \\
\leftarrow \text { subsequently exported to the broader commercial and technical } \\
\leftarrow \text { activity and any business partner }\end{array}$ \\
\hline
\end{tabular}

A learning organisation is one that can change from within itself. EasterbySmith (1999) states that implicitly, its underlying principle is an adaptive one where adaptation to environmental conditions or pressures leads to organisational learning and changes. Learning and changing faster than others can help to ensure the maintenance of any competitive edge or at the very least, increase the organisation's chances of survival. According to Pedler et al. (1996) the characteristics of the learning company are listed in Table 18.1.

This work has come about as a result of the recognition that evolution or transition to availability contracting will become a significant part of the operational activities of BAE Systems moving forward. BAE Systems is already evolving into a 'learning organisation' and the characteristics listed in Table 18.1 are all engendered in the EPSRC funded program entitled Support Service Solutions: Strategy and Transition (S4T). The material presented in this chapter was carried out as part of Work Package 3 within this program. It presents a strategy for the virtual simulation of maintenance planning processes and their execution for enhanced service provision. The main outputs required were WBS, the identification and quantification of sub-system level cost drivers (for subsequent use in 


\begin{tabular}{|l|lll|}
\hline \multirow{2}{*}{ Layout: T1 Standard SC } & Book ID: 192632_1_En & Book ISBN: 978-0-85729-188-2 \\
Chapter No.: 18 & Date: 14-5-2011 & Page: 336/352 \\
\hline
\end{tabular}

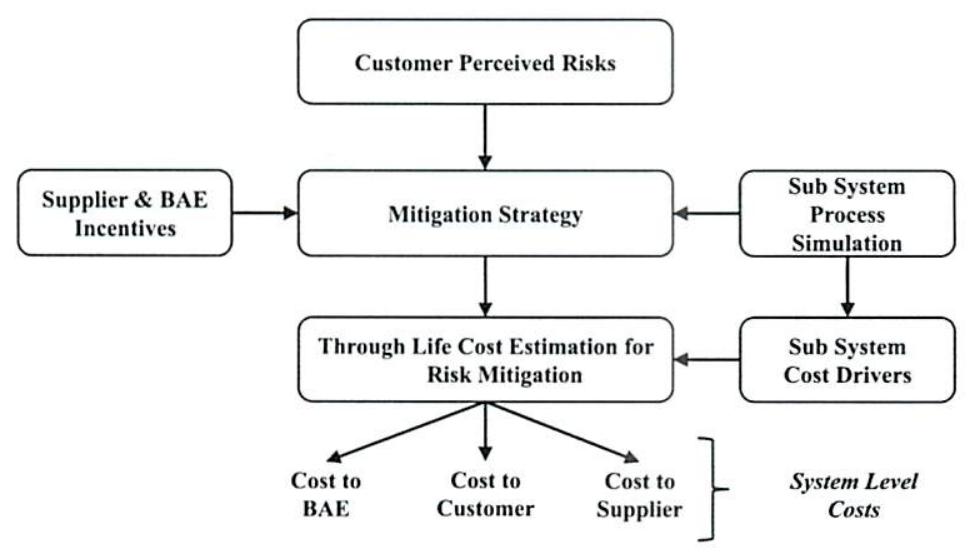

Fig. 18.2 Position of sub-system simulation activity within work package 3

system level cost models) and the provision of digital instructional materials. Digital manufacturing tools were used to deliver these requirements. The data flow diagram showing how simulation fits with the other research streams within Work Package 3 can be seen in Fig. 18.2.

Butterfield et al. (2007) have stated that the need to minimise the risk of commercial failure by developing leaner products has lead to the development of manufacturing simulation software systems which use simultaneous or concurrent engineering concepts for the design and engineering of new products across a range of industries. The way in which any complex assembly is constructed or de-constructed for maintenance, repair or overhaul (MRO) is an important consideration if a whole life approach is taken to product design and process development. Traditionally process design has not been supported by predictive technologies to the same degree as other areas of product design and development. To deal with this problem concurrent engineering concepts are now available in computer aided design (CAD) and computer aided engineering (CAE) tools and they are used to identify optimal process designs. Although to date, these tools have been used in a product design and manufacturing context, they are equally applicable to process design for the maintenance repair and overhaul (MRO) activities that are at the core of availability contracting. The simulation techniques that these systems offer allow process planners to define, validate, manage and deliver fully optimised manufacturing or MRO process specifications.

Although software vendors can provide 'off the shelf' solutions for the analysis of typical manufacturing processes, very often OEMs have company specific activities and requirements which do not fit into standard software versions. The CATIA $^{1}$ (Computer Aided Three-dimensional Interactive

\footnotetext{
1 CATIA is a 3D CAD modelling environment used for the design and specification of
} engineering components. 


\begin{tabular}{|l|lll|}
\hline Layout: T1 Standard SC & Book ID: 192632_1_En & Book ISBN: 978-0-85729-188-2 \\
Chapter No.: 18 & Date: $14-5 \cdot 2011$ & Page: 337/352 \\
\hline
\end{tabular}

18 Simulation Based Process Design Methods

Fig. 18.3 Pintle frame location within the front section of Panavia Tornado

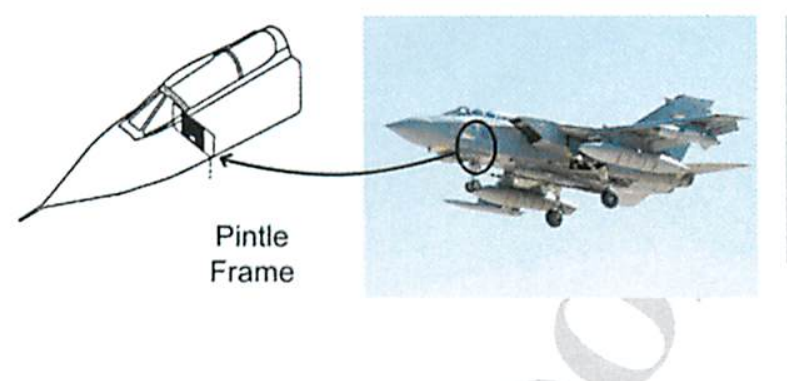

Application) and DELMIA ${ }^{2}$ (Digital Enterprise Lean Manufacturing Interactive Application) software modules used for this work were enhanced and customised where required, to suit the specific requirements of service support process development. An exemplar is presented which provides an evaluation of simulation methods on a 'proof of concept' basis. The exemplar is based on a mid life fatigue modification required on a sub-system within the twin-engined Panavia Tornado combat aircraft. The work shows how digital methods, originally developed for purely manufacturing applications, can be applied to a low volume/high complexity task based on the replacement of a pintle frame section. The pintle is a significant piece of internal structure in the front end of the aircraft, see Fig. 18.3. The application in this instance is based on the simulation of the removal and replacement of key structural components in order to demonstrate how the entire process can be designed and captured in a virtual environment. This, in turn, demonstrates how the methods used can be applied to the service of elements within a complex asset which were never designed to be replaced. This is an important example of the increasing complexity of defencebased service provision.

The work focuses on the development and validation of an optimal WBS and the main outputs are the process definition including task completion times (to facilitate cost prediction), the development of digital animations for process design purposes as well as instructional delivery. Butterfield et al. (2007) have demonstrated the utility of the method in a manufacturing context for improving operator learning through the use of animated work instructions. Butterfield et al. (2008) have shown improved management learning using concurrent digital working practices and Jin et al. (2009) for simulating manufacturing assembly times.

The work detailed in this chapter uses a CAD-based collaborative environment to develop this approach to bring simulation and optimisation strategies in line with the planning required for aerospace-based availability contracting at BAE Systems. The structure uses, defines and retains process data for a single subsystem in this case, but the hierarchical nature of the structure means that complete systems can be modeled. The end result is an integrated, collaborative environment containing the WBS which is developed from the manufacturing bill of

2 DELMIA is an integrated, 3D CAD based environment used for engineering process design and optimisation. 


\begin{tabular}{|l|lll|}
\hline Cayout: T1 Standard SC & Book ID: 192632_1_En & Book ISBN: 978-0-85729-188-2 \\
Chapter No.: 18 & Date: 14-5-2011 & Page: 338/352 \\
\hline
\end{tabular}

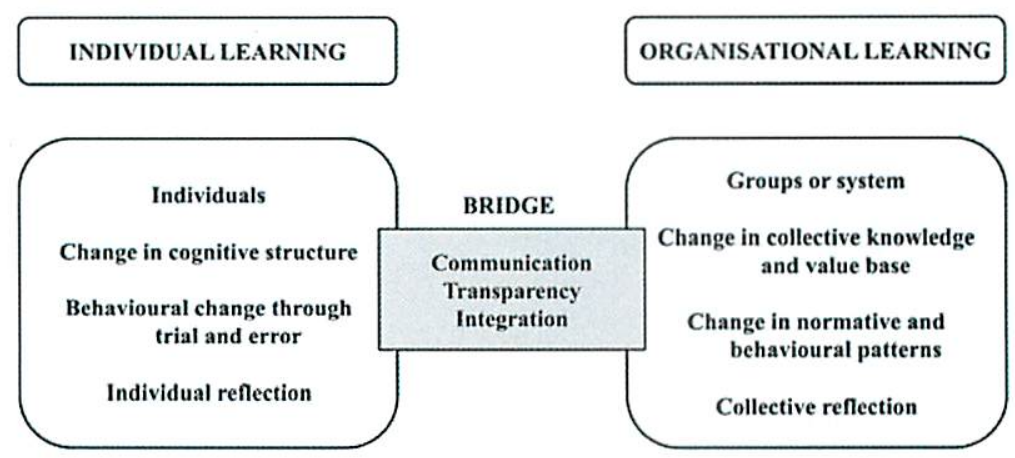

Fig. 18.4 Transformational bridge between individual and organisational learning, probst

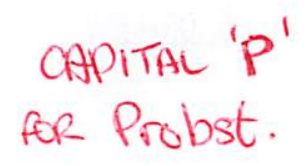

materials (MBOM). It defines the processes associated with service support activities and includes time and cost data for product assembly and dis-assembly as well as the animated process definitions. According to Probst and Buchel (1997) this then places the digital tools used for this work, in the role of a 'bridge' between the behaviours associated with the types of individual learning discussed by Butterfield et al. (2008) (managerial, operator etc.) and those required for the system level organisational learning which will aid the transition to availability contracting, see Fig. 18.4.

\subsection{Sub-System Level Simulation}

\subsubsection{Background}

The recent extension to the service life for the Tornado has given rise to the Mid Life Fatigue Programme (MLFP) within BAE Systems. A physical test programme has identified several critical airframe components which are approaching the end of their fatigue life. The original service expectation on the aircraft meant that these components were designed to operate up to the temporal point now reached by the aircraft. The extension to service means that these components must now be replaced.

The original design constraints and demands on these components did not include repair or replacement as they were expected to perform within design tolerances for the specific life span originally dictated. Many of these components are embedded deep within the airframe superstructure. Issues of access and method of change remain the dominant feature of the MLFP programme. Limitations of available data, as well as test case aircraft to assess concepts represents a strong case for digital simulation of MLFP activities in order to arrive at optimum, cost-effective solutions. 


\begin{tabular}{|l|lll|}
\hline Layout: T1 Standard SC & Book ID: 192632_1_En & Book ISBN: 978-0-85729-188-2 \\
Chapter No.: 18 & Date: 14-5-2011 & Page: 339/352 \\
\hline
\end{tabular}

18 Simulation Based Process Design Methods

Fig. 18.5 Pintle frame location

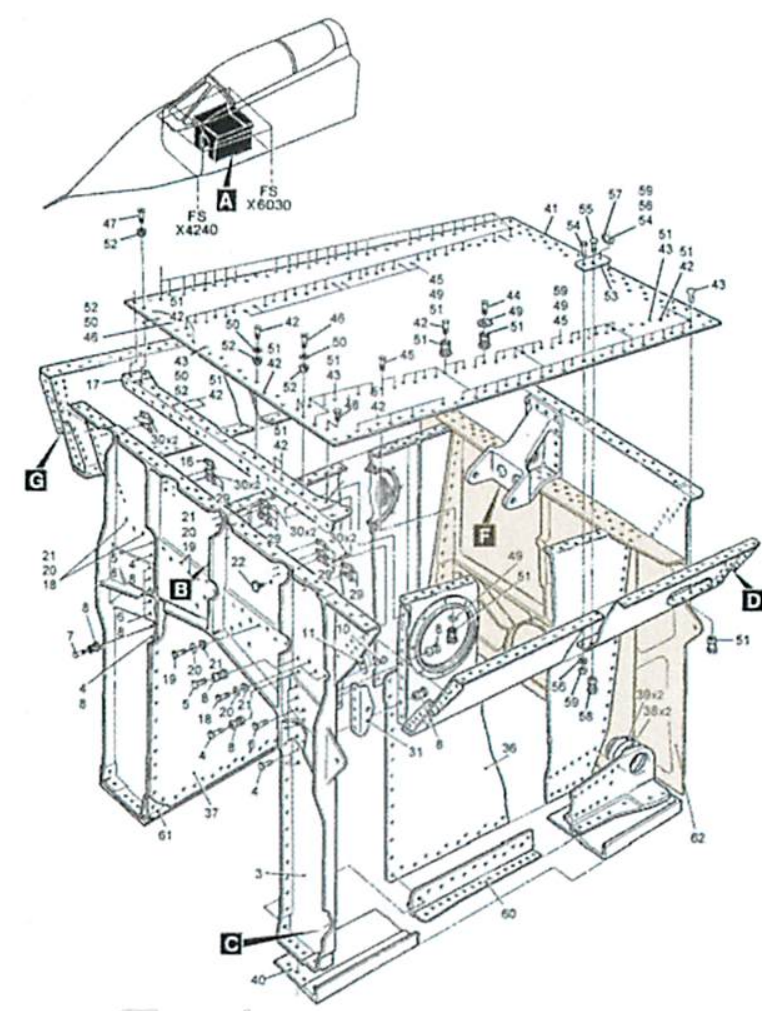

For the purposes of this work, Queen's University Belfast (QUB), in conjunction with BAE Systems Warton, have digitally simulated the replacement process of a major airframe structural component, the pintle frame, with a view to establish an optimum solution in both technique and cost. Utilising an integrated PPR structure, it was possible to model the relevant airframe components, associated fixtures and spatial constraints using DELMIA V5. The working methodology through the BOM within the DPM (Digital Process for Manufacture) environment and the associated work flow of the physical methodology. One specific proposal was then animated and ergonomics and clash detection utilised to establish the WBS.

\subsubsection{Test Case 'The Sub-System'}

Figure 18.5, shows the major portion of the airframe investigated. The panel to the rear of the seatwell box assembly, shown in exploded format, is the pintle frame. 


\begin{tabular}{|l|ll|}
\hline Layout: T1 Standard SC & Book ID: 192632_1_En & Book ISBN: 978-0-85729-188-2 \\
Chapter No.: 18 & Date: 14-5-2011 & Page: 340/352 \\
\hline
\end{tabular}

Fig. 18.6 Simulation of work space environment surrounding pintle frame

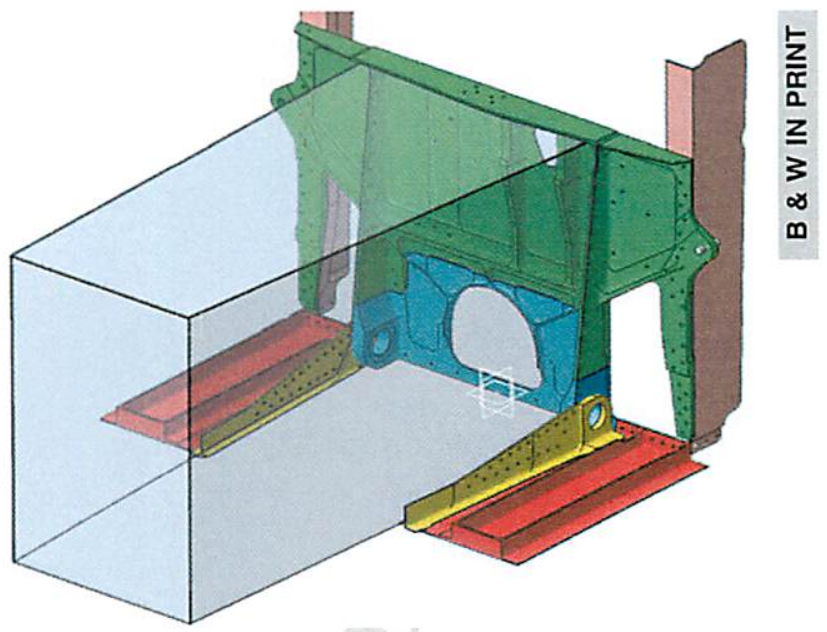

\subsubsection{Establish Maintenance Activities as Part of Standard BAE Systems Protocol}

Generic fitting activities are well established under the normal operating routines at BAE Systems. Pintle frame replacement constituted a significant challenge even with experienced fitting operatives. To gain access to the panel prior to replacement, it was first necessary to dis-assemble and remove the undercarriage. With access to the seatwell established, the hardware bolted to the interior surfaces of the surrounding structures was also removed and/or loosened from position to gain access to the pintle frame and create space within the seatwell, for the technician's working convenience.

From this point onwards, all activities are modelled within the digital environment. All movements, associated tooling and fixtures were used-as input-of $/$ inpot as. time dependant variables representing the sub-system level activities contained in the pintle replacement work package.

\subsubsection{Assembly Model of Environment}

Beginning with the major structural components, provided by BAE Systems in CATIA V4 format, all CAD data was translated into the V5 environment. A set of idealised shear walls were added to simulate the surrounding structural elements (see Fig. 18.6) for which only 2D data in the form of lofted drawings was available. This was the standard method for providing engineering data for a given part at the time when the Tornado was designed.

With the interior working volume established, the exterior surfaces were modelled to accurately reproduce the working environment. Again a simple idealised surface model of the exterior of the forward fuselage skin was used to provide relevant information pertaining to the movement of technicians, tooling 


\begin{tabular}{|c|c|c|c|}
\hline$\underline{\sigma}$ & $\begin{array}{l}\text { Layout: T1 Standard SC } \\
\text { Chapter No.: } 18\end{array}$ & $\begin{array}{l}\text { Book ID: 192632_1_En } \\
\text { Date: } 14 \cdot 5 \cdot 2011\end{array}$ & $\begin{array}{l}\text { Book ISBN: } 978-0-85729-188-2 \\
\text { Page: } 341 / 352\end{array}$ \\
\hline
\end{tabular}

18 Simulation Based Process Design Methods

Fig. 18.7 Human analysis simulation in pintle frame area

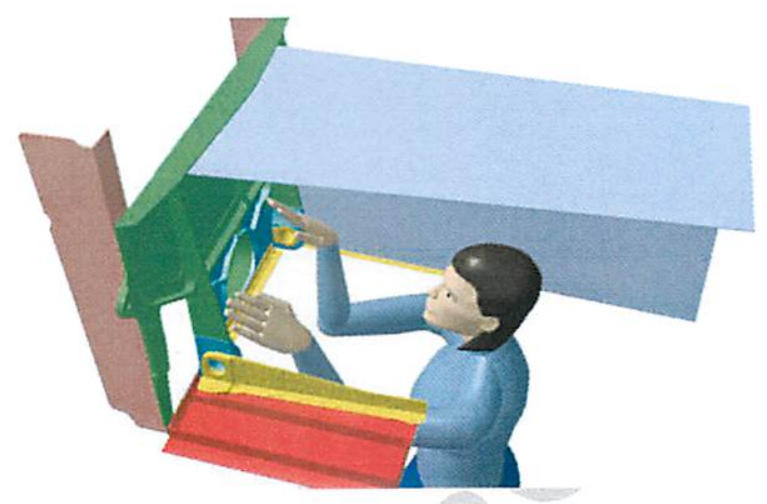

and fixtures around the work area. Information related to the distance between the workshop floor and the fuselage model was required to establish the limitations on technician movement around the work area.

\subsubsection{Human Considerations}

The shear wall surfaces were idealised to provide the physical boundaries or ergonomic constraints for the human analysis model. Figure 18.7 shows how a mannequin was used make an ergonomic assessment of the work area in front of the pintle frame. Here the mannequin can be seen in a position of disadvantageous medial rotation. This resulted from the lateral limitations of the work space in conjunction with the forced positioning with respect to the work piece height from the hanger floor. This example is an ideal illustration of how the effect of physical limitations can be analysed to express the optimum solution -ajoperator motion. In this case the analysis of posture indicates a limitation on lateral and transverse application of force available to the operator, and hence a clear design choice to focus on longitudinal motions to execute the task. In response, the associated tooling designed to meet this particular objective was designed with longitudinal motion as the key ergonomic requirement.

\subsubsection{Identification of Parts and Fasteners}

Fastener type and count were recorded based on the original manufacturing BOM. It must be noted here that CAD definitions of the fasteners does not exist and is not common practice in aerospace design. Fastener type, number and associated time for removal and replacement, however was defined for the purpose of time generation and their locations were determined from the $2 \mathrm{D}$ data provided by BAE Systems. To improve the efficiency of this task, a Visual Basic script was also devised based on an automated search which recovered hole sizes, quantities and depths directly from the feature tree in the CAD model see Fig. 18.8. Visual Basic 


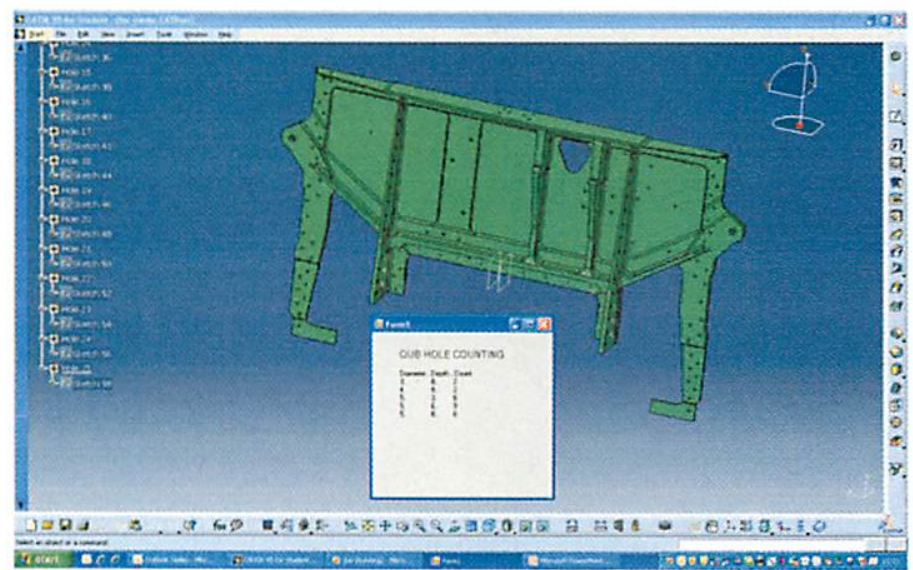

Fig. 18.8 Automated extraction of part data from feature tree in CATIA

is a programming language that enables the development of graphical user interface applications as well as access to databases using Data Access Objects, Remote Data Objects, or ActiveX Data Objects. In simple terms, this was a computer program designed to extract hole properties (sizes, quantities etc.) from the CAD model. By associating fastener types with given hole sizes, fastener counts could be established. The hole size and depth was equated directly with drilling time.

\subsubsection{Develop Simulation for Pintle Replacement}

Initial product assessments showed that the major dis-assembly of the airframe that was required to free the pintle frame for replacement was neither practicable nor cost effective. From this, the decision to re-work the pintle in situ was made. From this position, the first design constraints were established for any proposed engineering solutions.

A preliminary trade-off study was performed to establish the optimum method for the pintle replacement from a high level engineering perspective. The three solutions considered were:

- Full Automation-Computer controlled robotic machine installations

- Semi Automation-Hand held machine tools and guide templates

- Manual-The use of manually guided hand tools only

Each of the potential methods was rated according to six different metrics:

- Time-Required to perform tasks including set up, measurement or metrology and inspection; all value added activities

- Re-use-A measure of the potential utilisation of any hardware for future tasks not associated with the pintle replacement 

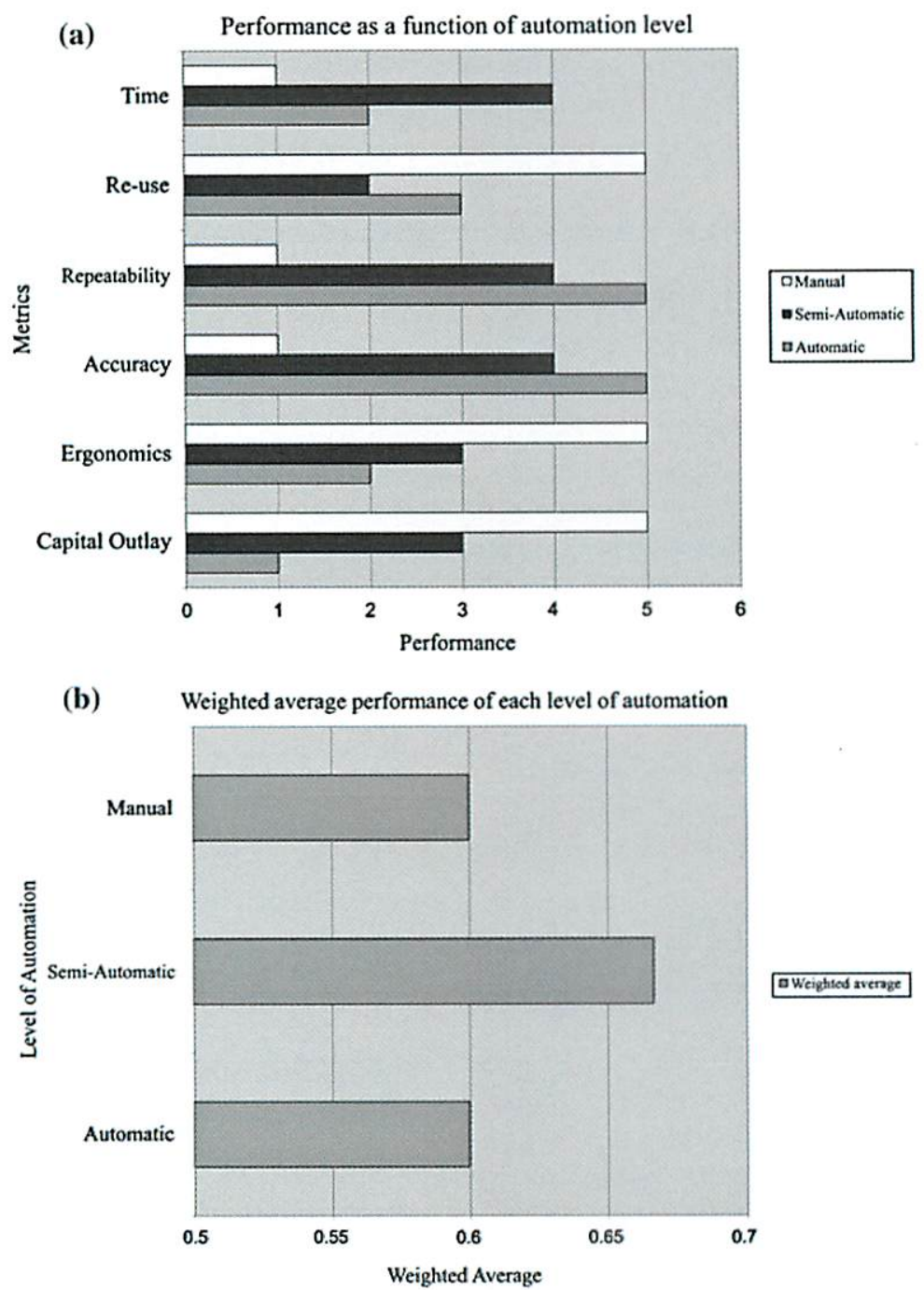

Fig. 18.9 Results of trade off study to establish high level methodology

- Repeatability - The recurrent holding of tolerances in all worked parts

- Accuracy-The capacity to meet geometric requirements with regard to the position of all worked surfaces with respect to existing geometry

- Ergonomics-Ease of operator movement (Includes measure of fatigue)

- Capital outlay-Cost of any associated hardware or consumables

The graphs shown in Fig. 18.9 illustrate the overall result of this decision making process. Graph (a) shows how each of the three methodologies performed with regard to the six metrics listed previously, as a mark out of a possible 
maximum of five where: $1=$ worst/low rating, $5=$ best/high rating. Graph (b) in Fig. 18.9 shows the weighted average of these values as a non-dimensional expression between 0 and 1 . This graph shows that, for the conditions used in this trade study, the semi-automatic methodology had the best combination of performance properties.

Having established the benefits of a semi-automated solution, a secondary set of design criteria were established. The need to escape the uncertainty in both repeatability and accuracy with the fully manual methodology, as well as the intrinsic high temporal cost, predicated a maximum utilisation of suitable machine tools. The limitations on such tooling, while including capital cost, were driven primarily by physical size. A survey of available hardware, performed for the trade off study, identified a number of miniaturised milling machines capable of carrying the appropriate tool bits and performing with the necessary power to cut the maximum skin thickness identified from the pintle geometry.

\subsubsection{Fixtures and Tooling}

The crux of the engineering problem presented here involves the fact that the replacement pintle pieces are newly manufactured. These have to be fitted to preexisting, well used airframes of variable, and most importantly un-quantified, dimensional stability. With this in mind, a decision was made to use a machining pattern or fixture that would facilitate accurate and repeatable removal of the redundant pintle material.

With the idealised machine tool modelled in the CAD environment, to provide the required dimensions for the interface with the new piece, it was possible to test the positions and motions of the tool to establish the optimum path. This was carried out as follows:

- Tool path-derived from the final geometry of the portion of the pintle which was to remain in situ, and the replacement piece to be introduced and fitted. The minimum number of movements and set ups required by the operator in execution of cutting. Clash detection with all surrounding components with respect to the mill dimensions

- Tool choice, cutting speed and feed rate-again derived from the final geometry, variation in material thickness, minimum tool movement during operation and best possible proximity of the mill to the work piece without clash

Choice of tooling implemented in the final design solution was established iteratively through the simulated environment including design, assembly and human analysis methods. For example, the mini-mill chosen for the machining operations was one of a small number of machines initially selected for its size characteristics. All primary tool choices had to be small enough to fit within the confined space of the pilot seatwell with the operator. From within the design environment, the tool path was established for the removal of material from the original pintle. From the assembly environment, it became apparent that the 


\begin{tabular}{|l|lll|}
\hline Layout: T1 Standard SC & Book ID: 192632_I_En & Book 1SBN: 978-0.85729-188-2 \\
Chapter No.: 18 & Date: 14-5.2011 & Page: 345/352 \\
\hline
\end{tabular}

proximity of the shear webs and pintle bush lugs to the tool path negated the use of some of the primary tooling choices due to a physical clash between the tools and the surrounding structure. From the human analysis environment, it could be seen that the physical limitations on the operator posture resulted in a severe reduction in the operator's capacity to apply any meaningful degree of lateral force when handling the tool. From this an engineering decision to select a tool which could be handled in a predominantly longitudinal manner was made.

One major problem associated with the overall task was the establishment of reliable datums on which to base all hardware. The replacement sections of the pintle frame will be manufactured off site using a fixed set of dimensional constraints, but the surrounding airframe components and their position with respect to one another cannot be assumed to be as per original design or replicant from one aircraft to another. With these conditions in mind, it was decided to select the main undercarriage bearing positions on the longerons as the most suitable datum. Since the longerons are major structural components responsible for the positioning of much of the rest of the airframe, it can be assumed that they are prone to the least digression from original specification, both in terms of intrinsic dimensions, and also with regard to position in respect to one another. By extension it is logical to assume that the digression of the pintle frame position with respect to the longerons is also limited. Finally, since the pintle frame shares the same bearing locations as the longerons it is sensible to fix the position of the new pintle section from these points and base the cutting geometry of the original pintle with respect to the insert. This ensures that when the new section is inserted and located correctly with respect to the bearing locations, the machined surfaces on the cut out of the original pintle are aligned correctly with the mating surfaces of the insert, regardless of any distortion present in the original pintle.

The design solution arrived at consists of a flat guide plate which locates on the bearing positions and alters between a horizontal position for the early cutting stages and vertical orientation for the latter stages. This plate has guide paths on its surface which correspond to pins on the mill allowing it to follow set paths which mimic the required cut out profile on the pintle frame. The translation between horizontal and vertical positions is to allow the change in orientation necessary to make the set of cuts that exist in different planes. This plate, like the mill, is available for repeated use on each aircraft without the need for any measurement or alteration. This particular feature represents a large time saving in the overall time required to perform the task. In addition to this plate, a drilling template for the positioning of holes in the outer webs of the pintle is also utilised.

Major structural components, idealised bounding surfaces and where data is available, the sub-components fastened to the pintle frame were assembled within the CAD environment. Parts, fasteners and the positioning of all relevant components were fixed. The BOM, held within the PPR hub, was then available for interrogation by the user. The final choice in milling machine was the Ricci Corp Mini-mill.

For the given material properties of the components and the maximum material thickness to be encountered, engineering rules were applied and a size up regime 


\begin{tabular}{|l|lll|}
\hline Layout: T1 Standard SC & Book ID: 192632_1_En & Book ISBN: 978-0-85729-188-2 \\
Chapter No.: 18 & Date: $\mathbf{1 4 - 5 \cdot 2 0 1 1}$ & Page: $\mathbf{3 4 6 / 3 5 2}$ \\
\hline
\end{tabular}

Fig. 18.10 Pintle frame with web material still in place

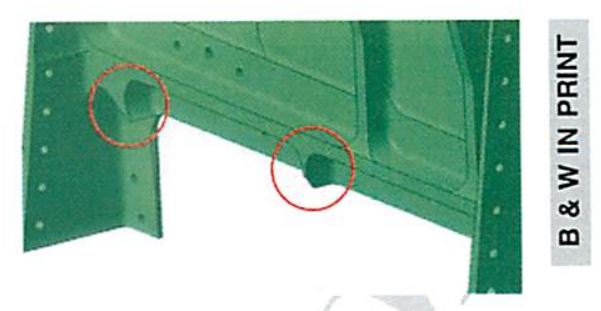

for the drilling operations was established as $2 \mathrm{~mm}$ to $3.5 \mathrm{~mm}$ to $5 \mathrm{~mm}$. A long taper flute drill is best suited to this material, however, the time deriving software for drilling operations that was used in this project, SEER Design for Manufacture, ${ }^{3}$ does not support such bits, hence, normal twist drills were used in this model. Since drilling templates were used where new holes were to be established without a pre-existing guide hole in a mating component, there was no requirement for spot drilling to ensure accurate hole placement. This represents a classic engineering decision within this model, to create a process which requires a minimum of specialised skill on the part of the operator, and hence mitigating against problems associated with the availability of highly skilled operators.

As mentioned previously, drilling operation times were established via SEER where the times associated for the drilling of any specific hole was established as a factor of drill size, hole depth, material properties and rotational speed of the drill. In a similar manner, the cutting speed of the mill was established through SEER also. The first milling operation involves the removal of the major portion of extraneous material from the pre-existing pintle. A $2 \mathrm{~mm}$ diameter plunge and cut bit of high speed steel with 4 flutes was chosen for this task. SEER has the capacity to model milling operations according to tool specifications (as listed above), the manner of cutting and the length and depth of the cutting path, or alternatively the volume of material to be removed. As the depth of the material, through any given cutting path was not consistent, each cut was modelled as a separate operation, the number of which was equal to the number of step changes in material depth through the entire cutting path. This provided optimal accuracy in the output time from the SEER model.

With the first cut complete and the waste material removed, the mill was fitted with a $10 \mathrm{~mm}$ diameter edge cutting bit of high speed steel with 8 flutes. With this tooling the internal edge of the pintle was finished to final dimensions. The final milling operation involves the removal of web material from the internal face of the pintle. The web material is highlighted in Fig. 18.10.

A $28 \mathrm{~mm}$ diameter face and edge cut tool of high speed steel and 16 flutes was selected. The final face profile is shown in Fig. 18.11. A three stage cutting plan was followed which avoided the possibility of machining in-accuracies due to removing too much material in one run.

\footnotetext{
${ }^{3}$ SEER is a registered trade mark for cost management software marketed by Galorath inc.
} 


\begin{tabular}{|l|lll|}
\hline Layout: T1 Standard SC & Book ID: 192632_1_En & Book ISBN: 978-0-85729-188-2 \\
Chapter No.: 18 & Date: 14-5-2011 & Page: 347/352 \\
\hline
\end{tabular}

18 Simulation Based Process Design Methods

Fig. 18.11 Pintle frame in

final state

Fig. 18.12 Placing of mill and tool lateral cuts

Fig. 18.13 Introduction of new pintle part

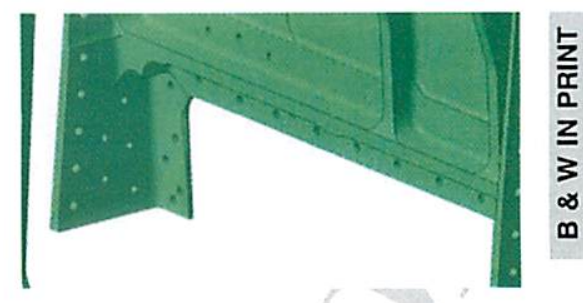

Each discrete drilling operation was modelled within DPM where the tooling can be seen moving around the work piece as per the process order. This in turn is also seen in the output work instructions.

\subsubsection{Process Definition}

The dis-assembly activities and all associated data were established using the simulation methods detailed above. A preliminary discussion with BAE Systems led to the following broad work stream order: Fastener strip, disassembly and removal of sub-components, clean down of exposed pintle frame, introduction of fixture(s) for cutting, machining and dressing, cut and dressing process for pintle frame, removal of now extraneous material from pintle frame, clean down, assembly of new pintle sub-part, fastening, re-assembly of sub-components, fastening and inspection. Each of these activities was broken down into sub-activities with different requirements in tooling, labour and hence time. The sub-activities relating to the work focussed directly on the pintle frame are derived directly from the simulation as optimised solutions.

Figures 18.12 and 18.13 , show 2 stages of the process required to replace the pintle frame. 


\begin{tabular}{|l|lll|}
\hline Layout: T1 Standard SC & $\begin{array}{l}\text { Book ID: 192632_1_En } \\
\text { Date: 14-5-2011 }\end{array}$ & $\begin{array}{l}\text { Book ISBN: 978-0-85729-188-2 } \\
\text { Page: } \mathbf{3 4 8 / 3 5 2}\end{array}$ \\
\hline 348 & & J. Butterfield and W. McEwan
\end{tabular}

Fig. 18.14 Inputs, process and outputs resulting from sub-system level simulation

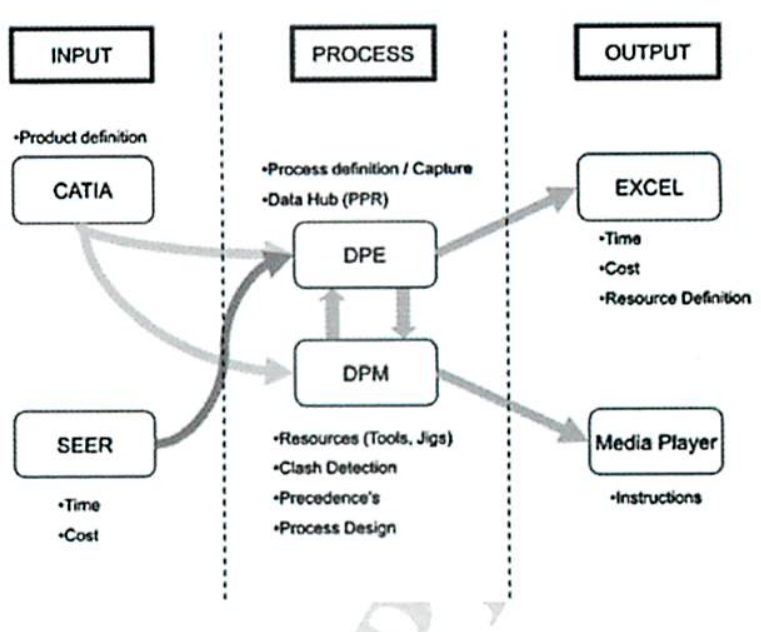

Each discrete component movement was animated within the CAD environment as they were removed or replaced. Clash detection studies were carried out to establish optimum pathways for each component movement. In conjunction, mannequins were utilised to perform an ergonomic assessment of the simulated activities.

With a working order established to the physical activities, each was recorded within Delmia Process Engineer (DPE) ${ }^{4}$ as discrete actions with their associated time and tooling requirement.

\subsubsection{Simulation Outputs}

A number of outputs were derived directly from the digital simulations. These were: Optimised work breakdown structure, identification of cost drivers, delivery of representative times for activities and the generation of instructional materials.

Figure 18.14 shows the overall process structure for the use of simulation methods to yield these outputs. Section 2.3 details the WBS which was defined in the CAD environment and subsequently recorded in DPE. The WBS was supplemented with process times and part counts.

The second output from this work package component was the identification of cost drivers. The drivers arising from the parameters within the sub-system simulation were found to include: Replacement parts, tooling, fixturing, fasteners and operator time (for dis-assembly/assembly and inspection/quality control).

The timing data generated from the simulations is in the form of the 'hands on' time associated with specific activities. When this is used for process costing at a

${ }^{4}$ DPE is the process modelling arm of the Dassault Systemes suit where discrete processes can be modelled, in order, and with associated attributes such as time. 
system level, these times must be supplemented with data associated with labour type and source, i.e., BAE Systems staff or customer personnel. A utilisation factor must also be applied to allow for 'non hands on' activities which are an integral part of an operator's working day. Consideration of learning curve impact is also critically dependant on labour type. Both utilisation and learning curve allowances will vary depending on the labour source and should be an important part of the system level costing strategy.

The final deliverable is represented by the animated work instructions. Clash detection, and ergonomic considerations, generated the most time conservative solution to the task of pintle frame repair. From the same digital simulation, instructional materials were generated to assist the execution of the pintle replacement activities. Butterfield et al. (2008) have shown that the use of animated instructional materials can reduce the learning curve resulting in lower manufacturing costs. It is expected that a similar result can be achieved with regard to maintenance and repair activities if operator learning is driven by animated work instructions. Here the process order and the specific details of each process have been shown as virtual movement of the components complete with fixtures and tools, as iss would occur in the real world scenario. Accompanying these animations are written instructions which appear as dialogue boxes at the points most appropriate to the specific processes. These instructions contain the details that are not immediately apparent from the animation. This includes such details as specific tool size or positioning of fixturing.

\subsection{Discussion}

The transition from a conventional supplier/customer relationship to an availability contract arrangement, constitutes a significant challenge for both parties at all levels within the enterprise-commercial, technical and human. According to Butterfield et al. (2009), the nature of the commercial relationship changes as previously separate business entities merge and self interests are replaced by the need for optimal 'co-performance'. Operational sustainability remains a challenge for any business entity under current political and economic conditions. Companies must become learning organisations which can react efficiently to changing market needs to retain any operational advantage or in extreme cases, simply to survive. The fact that BAE Systems have recognised the need for and initiated the S4T program means that it is evolving as a learning organisation. The characteristics listed in Table 18.1 are engendered in the S4T program as a whole and the simulation methods used for this work can be linked directly or indirectly to most of the same characteristics.

The aerospace exemplar presented here shows how simulation and the principles of digital manufacturing can be used to design service solutions for complex platform elements which were never intended for replacement. The functionality of the simulation framework allows complete system definition through the 
hierarchical summation of process definitions and parameters within individual sub-systems. The development, optimisation and retention of processes| knowledge in the virtual environment, increases the likelihood of a positive outcome for both the OEM and the customer by providing a framework by which the attributes of value co-creation discussed by $\mathrm{Ng}$ and Nudurupati (2010) and $\mathrm{Ng}$ et al. (2010a), can be facilitated using a controlled, measureable methodology. This enables the transformation of process structures (information), product definitions (materials and equipment) and people (instructional materials) in line with what will be required for the provision of platform availability. The simulations deliver process details from an engineering perspective, which include WBS for maintenance operations, delivery of representative times for 'hands on' activities (which can be used for resource optimisation and cost analysis), identification of cost drivers such as labour, tooling, fixturing and inventory and the generation of instructional materials. The outcomes can be used in turn, for system level cost modelling. The approach to the delivery of instructional materials in this case has been to use animated maintenance processes. The ability to carry out significant modifications in small batches is an important factor in service provision. This emphasises the need for an efficient means of transferring knowledge and instructing operators who may not be under the direct control of the OEM. In a service context they may have to carry out multiple tasks on a given system or across several platforms. The availability of animated instructional materials facilitates the operational agility and breadth of knowledge that an operator must have to deliver these efficiently.

The digital methods presented here are best suited for complex 'hard' engineering problems such as the pintle frame replacement. For other test and inspection activities the added value of this approach is questionable but the digital systems used for this work can still play a part in developing and delivering process definitions. Test and inspection activities can still be supported using a digital approach but the instructions would be based on static CAD images.

Digital manufacturing provides an integrated framework for the generation, management and delivery of engineering process definitions. Within a single enterprise, this facilitates concurrent activities between the engineering disciplines. The transparent and collaborative environment can be enhanced to include maintenance activities, as the process node in the manufacturing hub is extended to include the broader product lifecycle. The definition and optimisation of maintenance processes in a virtual environment using virtual assets reduces the uncertainty associated with availability contracting. Simulated process scenarios allow the process designer and implementer to reduce or eliminate exposure to risk and uncertainty by generating realistic data for important cost components.

This work has shown how digital methods can be used in support of the transition to availability based contracting. The benefits of using process simulation methods in support of this business model has been demonstrated on a proof of concept basis. The next step would be the implementation of the methods developed here starting with a pilot program covering a broader platform application working from subsystem to system level simulations. In order to exploit the utility of the methods presented here the question of how the simulation platform is managed has to be 


\begin{tabular}{|l|lll|}
\hline \multirow{2}{*}{} & Layout: T1 Standard SC & Book ID: 192632_1_En & Book ISBN: 978-0-85729-188-2 \\
Chapter No.: 18 & Date: $14-5 \cdot 2011$ & Page: $351 / 352$ \\
\hline
\end{tabular}

18 Simulation Based Process Design Methods

addressed. Process data related to MRO activities is generated at source by the platform manufacturer. When held as a central data repository within the PPR hub, process data can be accessed by individuals and disciplines across the enterprise. Levels of access and user privileges can be controlled by setting the relevant permissions. With current software versions, this can be achieved across existing enterprise wide networks but access can be a problem for outside parties due to security set ups etc. Data should also be available to both OEM and the customer and this has been recognised as an issue. Future versions of the software will be web mounted making access between enterprises possible.

\subsection{Conclusions}

A sub-system level exemplar based on the partial replacement of an aerospace structural panel has shown how simulation can deliver virtual process definitions for service support activities including work breakdown structure, key cost drivers and instructional materials. The utility of manufacturing simulation techniques in maintenance process design has been demonstrated. This requires the extension of a hierarchical PPR environment into the extended platform lifecycle where the assembly and dis-assembly processes associated with MRO activities can be modelled. The resulting process structure enables the determination of process sequences, labour hours and part counts. Instructional materials are developed concurrently with process design thereby eliminating the need for separate instructional authoring. This has been demonstrated at a sub-system level and the outcomes can feed into system level cost models. The PPR structure facilitates the process of knowledge generation, capture and retention thereby facilitating the transition of an OEM to availability contracting as a learning organisation.

The outcomes integrated with the other WP3 themes with digital methods supporting the Attributes of Value Co-Creation Mas developed by $\mathrm{Ng}$ et al. (2010a). The identification and quantification of sub-system cost drivers provided inputs for the cost modelling activity carried out by Roy et al. (2009), which in turn, informed the incentivisation work carried out by the University of Bath. Outside WP3, the QUB simulation outcomes provide the 'What?' and the 'How?' in terms of service support process definition and this information can be integrated with the University of Salford, WP4 activities related to the question of 'When?' in availability contracting.

\subsection{Chapter Summary Questions}

Having demonstrated the utility of digital methods for service provision on complex assets, any decision to move forward with this technology should be based on the outcomes presented here as well as the following: 
1. To what extent will existing customer assets be expected to perform beyond their original design life?

2. How compatible are original platform designs with the types of service required to extend their design life?

3. If provision for 1 and 2 above is required how will this be addressed in emerging services?

\section{References}

J. Butterfield, S. Crosby, R. Curran, S. Raghunathan, D. McAleenan, Network analysis of aircraft assembly processes using digital methods. ASME J. Comp. Inf. Sci. Eng. 7(3), 269-275 (2007)

J. Butterfield, R. Curran, G. Watson, C. Craig, S. Raghunathan, R. Collins, T. Edgar, C. Higgins, R. Burke, P. Kelly, C. Gibson, Use of digital manufacturing to improve operator learning in aerospace assembly. 7th AIAA Aviation Technology, Integration and Operations Conference (ATIO), 2nd Centre of Excellence for Integrated Aircraft Technologies (CEIAT) International conference on innovation and integration in aerospace sciences (Hastings Europa Hotel, Belfast, Northern Ireland, 2007)

J. Butterfield, A. McClean, Y. Yin, R. Curran, R. Burke, B. Welch, C. Devenny, Use of digital manufacturing to improve management learning in aerospace assembly. 26th ICAS Congress including the 8th AIAA ATIO Conference, Anchorage, Alaska, 2008

J. Butterfield, I. Ng, R. Roy, W. McEwan, Enabling value co-production in the provision of support service engineering solutions using digital manufacturing methods. Winter Simulation Conference, Austin, 2009

M. Easterby-Smith, L. Araujo, J. Burgoyne, Organizational learning and the learning organization: Developments in theory and practice, 1st edn. (Sage, London, 1999), pp. 130-156

Y. Jin, R. Curran, J. Butterfield, R. Burke, B. Welch, Intelligent assembly time analysis using a digital knowledge-based approach. J. Aerosp. Comput. Inf. Commun. 6(8), 1542-9423 (2009)

I.C.L. Ng, S. Nudurupati, Outcome-based service contracts in the defence industry-Mitigating the challenges. J. Serv. Manag. 21(5), 656-674 (2010)

I.C.L. $\mathrm{Ng}, \mathrm{S}$. Nudurupati, P. Tasker, Value co-creation in the delivery of outcome-based contracts for business-to-business service. AIM working paper series, WP No 77-May 2010 http://www.aimresearch.org/index.php?page=wp-no-77. Under review at J. Serv. Res. (2010a)

M. Pedler, J. Burgoyne, T. Boydell, The learning company: A strategy for sustainable development, 2nd edn. (McGraw-Hill Professional, NJ, 1996), pp. 3-10

G. Probst, B. Buchel, Organizational learning: The competitive advantage of the future (Prentice Hall, London, 1997), pp. 15-31

R. Roy, P. Datta, F. Romero, J. Erkoyuncu, Cost of industrial product-service systems (IPS2), CIRP International Conference on Life Cycle Engineering (LCE), Cairo, Egypt, 2009 
Book: 192632_1_En

Chapter: 18

\section{Springer}

\section{Author Query Form}

\section{Please ensure you fill out your response to the queries raised below and return this form along with your corrections}

Dear Author

During the process of typesetting your chapter, the following queries have arisen. Please check your typeset proof carefully against the queries listed below and mark the necessary changes either directly on the proof/online grid or in the 'Author's response' area provided below

\begin{tabular}{|c|l|c|}
\hline Query & \multicolumn{1}{|c|}{ Details required } & Author's response \\
\hline 1. & $\begin{array}{l}\text { Probst (1997) has been } \\
\text { changed to Probst and } \\
\text { Buchel (1997) as per the } \\
\text { reference list. Please check } \\
\text { and confirm. }\end{array}$ & \\
\hline
\end{tabular}

